Канд. техн. наук Ю.В. Глазунов,

Y. Glazunov

\title{
МІЦНІСТЬ БЕТОНУ ПРИ ЗОВНІШНЬОМУ АРМУВАННІ КОНСТРУКЦІЙ
}

\section{STRONG OF BETON BY INCULCATE OUTWARD ARMATURA}

\author{
Представив д-р техн. наук, професор А.А. Плугін
}

\begin{abstract}
Постановка проблеми у загальному вигляді, іiі зв'язок 3 важливими науковими та практичними завданнями. 3 розвитком виробничих сил у галузі будівництва виникає необхідність упровадження все більш ефективних i економічних конструкцій. Бетон у поєднанні зі стальною арматурою виявляється основним матеріалом для житлово-громадянського, промислового, енергетичного, транспортного та сільськогосподарського будівництва.
\end{abstract}

Відомо, що основні напрямки прогресу в сучасних будівельних конструкціях належним чином пов'язані 3 проблемою економії сталі. Заміна сталевих конструкцій залізобетонними надає можливість економити сталь, але це не завжди пов'язано 3 економією грошових коштів. Тому поряд 3 пошуками успішно конкуруючих рішень у залізобетоні стимулюється розвиток інших комплексних матеріалів і конструкцій, зокрема сталебетонних.
Збірні та монолітні конструкції із зовнішнім армуванням одержали розповсюдження в різних галузях будівництва в нашій країні та за кордоном. Цьому сприяли розширення галузі застосування залізобетону (у тому числі для спеціальних споруд енергетичного та гідротехнічного будівництва), технікоекономічна ефективність таких конструкцій, а також можливість використання зовнішньої арматури як опалубки при монолітному способі будування.

Концентроване розташування листової арматури на зовнішніх гранях сталебетонних конструкцій дозволяє знизити їх масу, зменшити розміри перерізу порівняно 3 залізобетонними конструкціями та одержати економію сталі при однаковій висоті.

Аналіз останніх досліджень та публікацій. У роботах [1-3] зазначено важливість впровадження конструкцій із зовнішнім армуванням як найбільш 
економічних конструкцій порівняно 3 традиційними залізобетонними. Економічність таких конструкцій забезпечується за рахунок більш раціонального використання матеріалів.

У науковій праці [1] відмічено, що армування бетону зовнішньою оболонкою сприяе підвищенню міцності такого конструктивного елемента, як сталебетон. Досягаються найкращі показники щодо роботи бетону при навантаженні, у результаті чого зменшуються усадочні деформації і підвищується опір бетону дії агресивного середовища.

У роботі [2] надано дослідження фізико-механічних властивостей матеріалів, які знаходяться у складі сталебетонних конструкцій. Показано вплив матеріалів на несучу здатність і деформації сталебетонних елементів. Визначено геометричні характеристики поперечного перерізу конструкції зі сталебетону. Показано теоретичні рішення для оцінки напруженодеформованого стану згинаючих стержнів 3 урахуванням об'ємного напруженого стану бетонного ядра.

У роботах [3-5] розроблено методику розрахунку сталебетонних елементів прямокутного поперечного перерізу на міцність при осьовому стиску. Показано взаємодію стальної оболонки і бетонного ядра, яке працює в умовах об'ємного напруженого стану зі змінними параметрами деформування. Наведено чисельні розрахунки напруженодеформованого і граничного стану перерізу сталебетонної конструкції.

Основний матеріал статті. Метою дослідження $\epsilon \quad$ проведення експериментально-теоретичних досліджень впливу способів передачі зовнішнього поздовжнього навантаження на несучу здатність сталебетонних колон прямокутного перерізу.

Основне завдання, яке необхідно було вирішити у наведеному дослідженні, таке:

- розроблення способу розрахунку сталебетонних конструкцій на центральне стиснення при передачі поздовжнього навантаження на кожний конструктивний елемент окремо;

- визначення наявності сил зчеплення між бетоном і сталлю та їх вплив на несучу здатність сталебетонних колон;

- перевірка міцності сталебетонних балочних конструкцій при роботі на згин 3 визначенням сил зсуву по площині 3'єднання листової арматури і бетону по довжині балки;

- одержання експериментальних даних про вплив способів передачі поздовжнього навантаження на характер деформування та зруйнування сталебетонних колон.

У даній роботі розроблено способи розрахунку сталебетонних конструкцій при різних виявах зовнішнього поздовжнього навантаження. Експериментальними дослідженнями виявлено вплив способів прикладення зовнішнього поздовжнього навантаження на несучу здатність сталебетонних конструкцій i надано порівняння з теоретичними результатами.

Експериментальні дослідження сталебетонних зразків проведено на осьове стиснення при передачі поздовжнього навантаження на бетон і сталь одночасно; на стальну обойму в зразку, заповненому бетоном; на стальну обойму в зразку без бетонного ядра.

При таких способах передачі навантажень на поздовжніх сторонах пластин обойми згинальні моменти відсутні. Це дозволяє розглядати металеву обойму як окремі шарнірно оперті пластини, завантажені в поздовжньому і в поперечному напрямках. При цьому припускається, що односторонні контактні зв'язки між заповнювачем і обоймою не перешкоджають згину пластин назовні.

Для експериментальних досліджень було виготовлено 4 серії зразків, висота яких - 500 мм. Відношення розмірів поперечних перерізів в/ $\alpha$ складають 1,0 ; 1,$3 ; 1,6 ; 2,0$. Товщина оболонки $2 ; 3,1 ; 3,8$; 4,1 мм. Оболонки виготовлялись 3 двох 
стальних листів, зігнутих у вигляді швелерів і зварених по всій довжині.

Для вищезазначених матеріалів були проведені стандартні випробування. Міцність і деформації бетону на стиснення визначались за результатами випробувань кубів 100x100x100 мм і призм. Характеристики деформацій і міцності при розтягуванні бетону визначались на зразках 40x40x80 мм. Деформації в бетонних призмах фіксувались поздовжніми i поперечними тензодатчиками в середньому перерізі по довжині кожної призми.

Характеристики міцності та деформацій сталі отримано в результаті випробувань на розтягування штаби 3 такими розмірами: $500 \times 40 \times 2 ; 500 \times 20 \times 2$; $500 \times 40 \times 4$ мм, які були вирізані з оболонок сталебетонних колон. Деформації при цьому визначались тензодатчиками та оптичними тензометрами.
Сталебетонні колони випробувались на гідравлічному пресі ПММ-250. Опорні пристосування забезпечували шарнірну схему закріплення зразка. Спеціальні захоплювачі дозволяли випробовувати колони з різним поперечним перерізом. У процесі випробувань вимірювались поздовжні і поперечні деформації. Для цього в зразках по всьому периметру середнього по довжині перерізу наклеювалися тензодатчики в поперечному та поздовжньому напрямках.

Центрування колон у процесі випробування виконували згідно 3 показниками тензодатчиків. Колони завантажувалися етапами з витримками для зняття показників вимірювальних приладів. Відрахування по приладах починали знімати з початку навантаження.

Розглянемо приклад передачі сили одночасно на сталь і бетон (рис. 1).
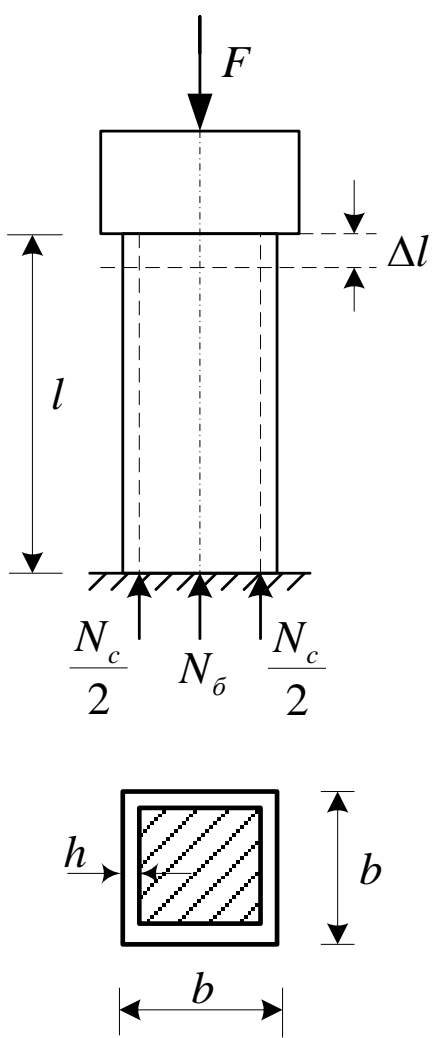

Рис. 1. Приклад передачі сили одночасно на сталь і бетон 
Запишемо умови рівноваги:

$$
N_{c}+N_{\sigma}=F \text {. }
$$

Умова сумісності деформацій:

$$
\begin{gathered}
\Delta l_{c}=\Delta l_{\sigma} ; \\
\frac{N_{c} l}{E_{c} A_{c}}=\frac{N_{\sigma} l}{E_{\sigma} A_{\sigma}} .
\end{gathered}
$$

Площа перерізу оболонки:

$$
A_{c}=2 b h+2(b-2 h) h=4 h(b-2 h) \text {. }
$$

Площа перерізу бетону:

$$
\begin{aligned}
& A_{\sigma}=(b-2 h)^{2} \text {. } \\
& b_{\sigma}^{\prime}=b_{\sigma} \cdot \varepsilon_{\sigma}^{\prime}=b_{\sigma} v_{\sigma} \varepsilon_{\sigma}=b_{\sigma} v_{\sigma} \frac{N_{\sigma}}{E_{\sigma} A_{\sigma}}=\frac{v_{\sigma} N_{\sigma}}{E_{\sigma}} \cdot \frac{b_{\sigma}}{A_{\sigma}}=\frac{v_{\sigma} N_{\sigma}}{E_{\sigma}} \cdot \frac{1}{b-2 h} .
\end{aligned}
$$
деформації:

$$
\varepsilon_{\sigma}^{\prime}=v_{\sigma} \varepsilon_{\sigma}, \varepsilon_{c}^{\prime}=v_{c} \varepsilon_{c}
$$
то $\varepsilon_{\sigma}^{\prime}<\varepsilon_{c}^{\prime}$.

Враховуючи, що $\varepsilon_{\sigma}=\varepsilon_{c}$, a $v_{\sigma}<v_{c}$,

Розмір поперечного перерізу бетону після деформації (рис. 2) визначається так:

Внутрішній розмір поперечного перерізу оболонки:

$$
b_{c}^{\prime}=b_{\sigma} \cdot \varepsilon_{c}^{\prime}=b_{\sigma} v_{c} \varepsilon_{c}=b_{\sigma} v_{c} \frac{N_{c}}{E_{c} A_{c}}=\frac{v_{c} N_{c}}{E_{c}} \cdot \frac{1}{4 h} .
$$

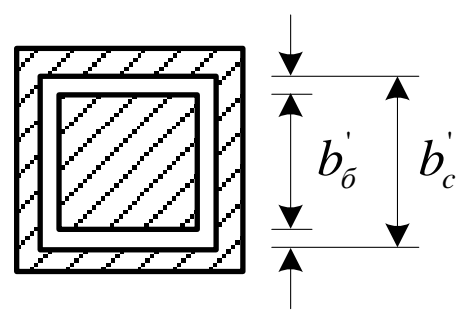

Рис. 2. Поперечний переріз бетону після деформації

Зчеплення бетону зі стальною оболонкою:

$$
\frac{b_{c}^{\prime}-b_{\sigma}^{\prime}}{2}=\frac{\frac{v_{c} N_{c}}{E_{c}} \cdot \frac{1}{4 h}-\frac{v_{\sigma} N_{\sigma}}{E_{\sigma}} \cdot \frac{1}{b-2 h}}{2}=\frac{v_{c} N_{c}}{E_{c}} \cdot \frac{1}{8 h}-\frac{v_{\sigma} N_{\sigma}}{E_{\sigma}} \cdot \frac{1}{2(b-2 h)} .
$$


Пластини, які входять до обойми, можуть утратити стійкість. За відсутності бетонного ядра, коли стискальні напруження могли б дорівнювати своєму критичному значенню, починалось би випинання і поперечні перерізи обойми могли б скривитися. Тоді поздовж кутів між стінками обойми, що випинає, не буде згинальних моментів, i кожна стінка

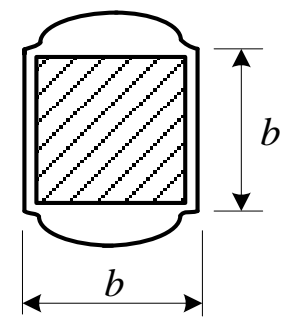

Рис. 3. Деформація при випинанні пластинки знаходиться в умовах стисненої прямокутної пластинки 3 вільно опертими краями [1]. За наявності ж бетонного ядра деформація при випинанні буде іншою (рис. 3), у зв'язку з чим стінку обойми необхідно розглядати як стиснену пластинку 3 поздовжніми защемленими краями (рис. 4).

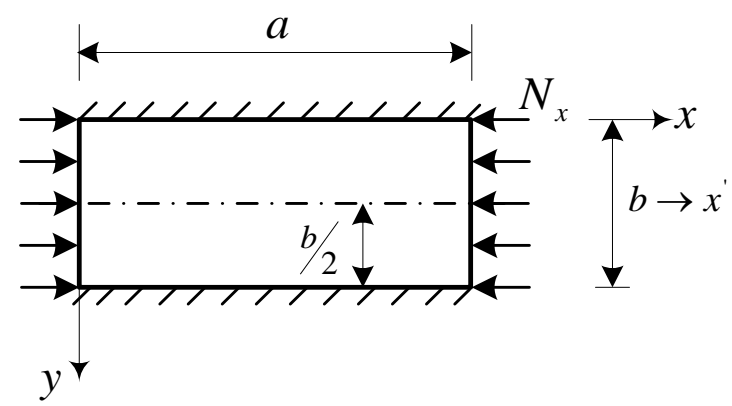

Рис. 4. Стиснена пластинка 3 поздовжніми защемленими краями вигляд:

Диференціальне рівняння зігнутої поверхні пластинки при цьому буде мати такий

$$
\frac{\partial^{4} \omega}{\partial x^{4}}+2 \frac{\partial^{4} \omega}{\partial x^{2} \partial y^{2}}+\frac{\partial^{4} \omega}{\partial y^{4}}=-\frac{N_{x}}{D} \cdot \frac{\partial^{2} \omega}{\partial x^{2}}
$$

Далі розглянемо розв'язання у такому вигляді:

$$
\omega=f(y) \sin \frac{m \pi x}{a},
$$

що задовольняє граничні умови

$$
\omega=0 \text { и } M_{x}=\left(\frac{\partial^{2} \omega}{\partial x^{2}}+M \frac{\partial^{2} \omega}{\partial y^{2}}\right)=0
$$

при $\mathrm{x}=0$ i x $=\mathrm{a}$.

Якщо підставити вираз (10) у вираз (9) і скоротити на $\sin (m \pi x / a)$, одержимо 


$$
\frac{\partial^{4} f}{\partial y^{4}}-2\left(\frac{m \pi}{a}\right)^{2} \frac{\partial^{2} f}{\partial y^{2}}+\left[\left(\frac{m \pi}{a}\right)^{2}-\frac{\sigma_{x} h}{D}\right]\left(\frac{m \pi}{a}\right)^{2} f=0
$$

Від рівняння (9) в окремих похідних переходимо до звичайного диференціального рівняння. Інтегрування рівняння (11) в даному випадку не дуже важке, у більш складних задачах воно може бути виконано за допомогою різних наближених методів, наприклад метода Бубнова-Галеркина.
Повертаємось до рівняння (11) та уведемо таке позначення:

$$
\frac{m \pi}{a}=\lambda
$$

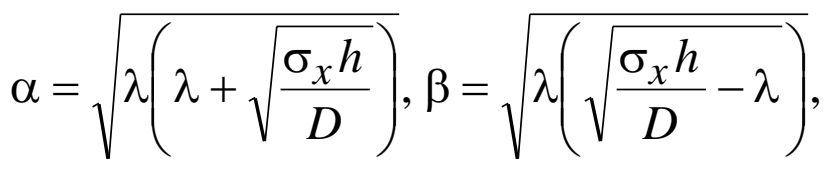

одержимо інтеграл рівняння (11) у такому вигляді:

$$
f(y)=C_{1} \operatorname{ch} \alpha y+C_{2} \operatorname{sh} \alpha y+C_{3} \cos \beta y+C_{4} \sin \beta y .
$$

Система має розв'язок за умови рівності нулю визначника системи:

$$
(\operatorname{ch} \alpha b-\cos \beta b)^{2}-\left(\operatorname{sh} \alpha b+\frac{\beta}{\alpha} \sin \beta b\right)\left(\operatorname{sh} \alpha b-\frac{\alpha}{\beta} \sin \beta b\right)=0 \text {. }
$$

3 рівняння (13) маємо

$$
\alpha^{2}+\beta^{2}=2 \lambda \sqrt{\frac{\sigma_{x} h}{D}}, \quad \alpha^{2}-\beta^{2}=2 \lambda^{2}
$$

Використовуючи рівняння (15) і (16), визначаємо критичне напруження [4]. Введемо такі позначення:

$$
\xi=\frac{a b}{2} ; \eta=\frac{\beta b}{2}
$$

Рівняння (16) набуває такого вигляду:

$$
\sigma_{x}=\frac{D}{h} \frac{4}{\pi^{2} b^{2}}\left(\frac{a}{m b}\right)^{2}\left(\xi^{2}+\eta^{2}\right)^{2}
$$




$$
\xi^{2}-\eta^{2}=\frac{1}{2}\left(\frac{m b \pi}{a}\right)^{2} \rightarrow \xi=\sqrt{\eta^{2}+\frac{\pi^{2}}{2}\left(\frac{m b}{a}\right)^{2}}
$$

Визначаємо величини $\xi$ і $\eta$ з рівняння (19) і за формулою (18) знаходимо критичне значення $\sigma_{x}$.

Подамо критичне напруження як

$$
\sigma_{\kappa p}=K \frac{\pi^{2} D}{b^{2} h}
$$

де

$$
K=\frac{4}{\pi^{2}}\left(\frac{a}{m b}\right)^{2}\left(\xi^{2}+\eta^{2}\right)^{2}
$$

Знаходимо значення $\frac{a}{m b}$, при якому $K \rightarrow \min$.

Маємо

$$
\frac{a}{m b}=0.663, \eta=2.05186, \xi=3.92894 \mathrm{i} K_{\min }=6.968
$$

Тоді, наприклад, при $\mathrm{b}=40 \mathrm{~cm}, \mathrm{~h}=0.5 \mathrm{~cm}, \quad E=2 \cdot 10^{5}$ мПа, $v=0.3$

$$
\begin{aligned}
D & =\frac{E h^{3}}{12\left(1-v^{2}\right)}=\frac{2 \cdot 10^{5} \cdot 10^{6} \cdot 0.5^{3} \cdot 10^{-6}}{12\left(1-0.3^{2}\right)}=2289 \mu, \\
\sigma_{k p} & =6.968 \frac{\pi^{2} \cdot 2289}{40^{2} \cdot 10^{-4} \cdot 0.5 \cdot 10^{-2}} \cdot 10^{-6}=196.8 \mathrm{M} \Pi a .
\end{aligned}
$$

Критична сила

$$
F_{\kappa p}=\sigma_{\kappa p} A_{c}=196.8 \cdot 10^{6} \cdot 10^{-3} \cdot 4 \cdot 0.5(40-2 \cdot 0.5) \cdot 10^{-4}=1535 \kappa H .
$$

Якщо $N_{c}=F_{k p}$, то за виразом (5) для класу бетону міцністю В25:

$$
N_{\sigma}=1535 \frac{30 \cdot 10^{3}(40-2 \cdot 0.5)}{2 \cdot 10^{5} \cdot 4 \cdot 0.5}=4490 \kappa H .
$$

Визначаємо напруження в бетоні: 


$$
\sigma_{\sigma}=\frac{N_{\sigma}}{A_{\sigma}}=\frac{4490 \cdot 10^{3}}{(40-2 \cdot 0.5)^{2} \cdot 10^{-4}} \cdot 10^{-6}=29.52 \text { мПа }>25 .
$$

При $N_{\tilde{\sigma}}^{\text {пред }}=25 \cdot 10^{6} \cdot 10^{-3} \cdot 39^{2} \cdot 10^{-4}=3802.5 \kappa \mathrm{H}$

$$
N_{c}=\frac{3802.5 \cdot 2 \cdot 10^{5} \cdot 4 \cdot 0.5}{30 \cdot 10^{3} \cdot 39}=1300 \kappa H .
$$

Граничне навантаження:

$$
F_{n p}=N_{c}+N_{\sigma}=1300+3802.5=5102.5 \kappa H .
$$

При даному навантаженні бетон не бере участі в його прийнятті, і воно все передається на оболонку. А оскільки $F_{n p}>F_{k p}(5102.5>1535.0)$, оболонка втрачає стійкість.

«Відшаровування» бетону, враховуючи вираз (8), при граничному навантаженні $F_{n p}=5102.5 \kappa H:$

$$
\begin{aligned}
& \frac{b_{c}^{\prime}-b_{\sigma}^{\prime}}{2}=\frac{0.3 \cdot 1300 \cdot 10^{3} \cdot 10^{3}}{2 \cdot 10^{5} \cdot 10^{6} \cdot 8 \cdot 0.5 \cdot 10^{-2}}-\frac{0.18 \cdot 3802.5 \cdot 10^{3} \cdot 10^{3}}{30 \cdot 10^{3} \cdot 10^{6} \cdot 2(40-2 \cdot 0.5) \cdot 10^{-2}}= \\
& \frac{3.9}{80}-\frac{0.18 \cdot 3802.5}{600 \cdot 39}=0.04875-0.02925=0.0195 \mathrm{MM} ; \\
& \varepsilon_{\sigma}=\frac{N_{\sigma}}{E_{\sigma} A_{\sigma}}=\frac{3802.5 \cdot 10^{3}}{30 \cdot 10^{3} \cdot 10^{6} \cdot 39^{2} \cdot 10^{-4}}=0.083 \ldots \cdot 10^{-2} ; \\
& \varepsilon_{\sigma}=\frac{N_{c}}{E_{c} A_{c}}=\frac{1300 \cdot 10^{3}}{2 \cdot 10^{5} \cdot 10^{6} \cdot 4 \cdot 0.5 \cdot 39 \cdot 10^{-4}}=0.083 \ldots \cdot 10^{-2} .
\end{aligned}
$$

Для випробуваного зразка (рис. 5):

$$
\begin{aligned}
& A_{\sigma}=(13-2 \cdot 0.2)^{2}=158.76 \mathrm{~cm}^{2}, \\
& A_{c}=4 \cdot 0.2(13-2 \cdot 0.2)=10.08 \mathrm{~cm}^{2} .
\end{aligned}
$$

При $\frac{a}{m b}=0.663, m=\frac{a}{0.663 b}=\frac{50}{0.663 \cdot 13}=5.8$ півхвилі.

$$
D=\frac{E h^{3}}{12\left(1-v^{2}\right)}=\frac{2 \cdot 10^{5} \cdot 10^{6} \cdot 0.2^{3} \cdot 10^{-6}}{12\left(1-0.3^{2}\right)}=\frac{800}{5.46}=146.5 \mathrm{HM} .
$$




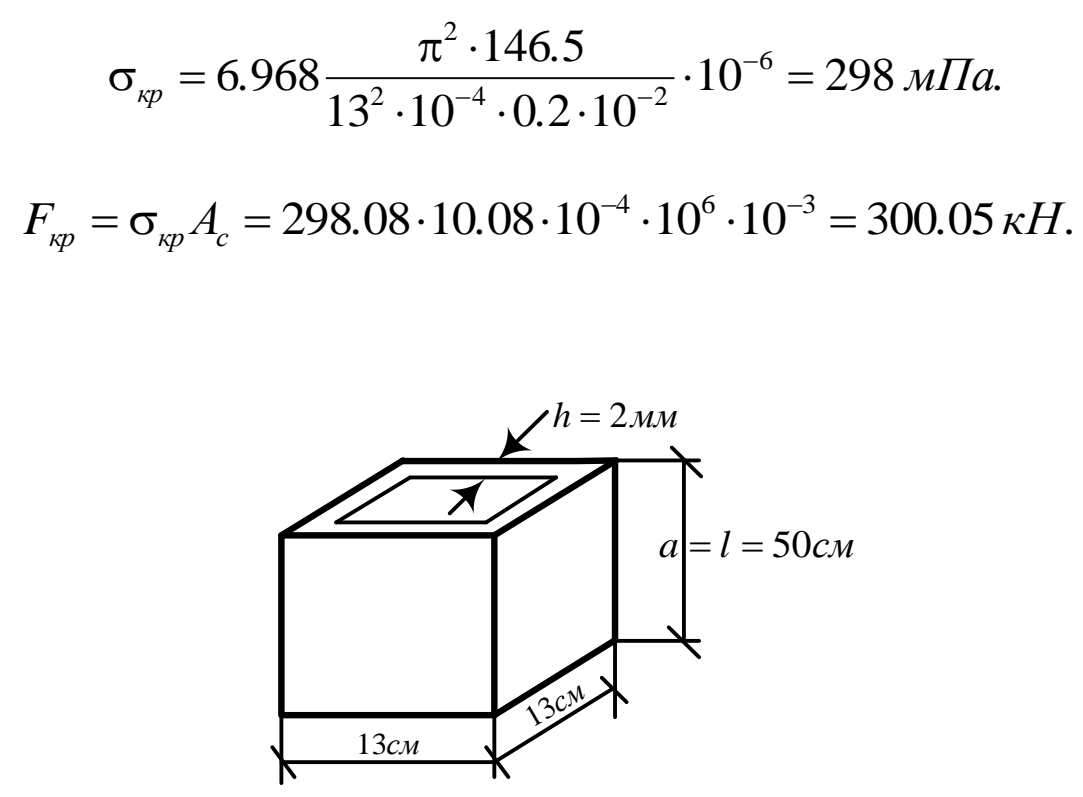

Рис. 5. Схема випробуваного зразка

При $N_{c}=F_{\kappa p}$

$$
\begin{aligned}
& N_{\sigma}=300.46 \frac{30 \cdot 10^{3}(13-2 \cdot 0.2)}{2 \cdot 10^{5} \cdot 4 \cdot 0.2}=710 \kappa H ; \\
& \sigma_{\sigma}=\frac{710 \cdot 10^{3}}{(13-2 \cdot 0.2)^{2} \cdot 10^{-4}} \cdot 10^{-6}=44.7 м \Pi a>36 \text { мПа. }
\end{aligned}
$$

Навантаження на зразок визначається так:

$$
F_{n p}=N_{\tilde{\sigma}}^{\kappa p}+N_{c}=572+242=814 \kappa H .
$$

Навантаження, при якому зразок зруйнувався:

$$
\begin{gathered}
F_{\text {on }}=880 \kappa H . \\
\Delta F=\frac{880-814}{814} \cdot 100=8 \% .
\end{gathered}
$$

Перевищення дослідного навантаження від розрахункового на $8 \%$ пояснюється збільшенням границі міцності бетону при твердінні (тужавленні) в обоймі без доступу повітря.
Слід зазначити, що при більшій товщині стальних стінок колони руйнування оболонки буде відбуватися без втрати стійкості стінки. Порядок визначення навантаження, при якому буде 
руйнування, у цьому випадку повинен виконуватись за іншою схемою [5].

На ділянці від початку навантаження і до ступеня досягнення значення максимальної сили зчеплення $F_{34}$ зв'язок між дотичними напруженнями i деформаціями граничного шару прямолінійний. Процес видавлювання бетонної призми супроводжується, як правило, підвищенням навантаження над граничним, яке характеризує збільшення сил зчеплення в 1,2-3 рази.

Зростання навантаження при видавлюванні може бути пояснено недосконалістю внутрішньої поверхні оболонки (непрямолінійністю стінок, різними поперечними розмірами оболонки по довжині і т. ін.) і силами тертя, які відбуваються в результаті стиснення металевої оболонки бетоном. Цьому стисненню сприяє ущільнення бетону вібруванням. Недосконалості, які виникають при виготовленні, потребують додаткових зусиль для продавлювання бетонної призми.

Експериментальними дослідженнями підтверджено висновки теоретичної частини стосовно підвищення міцності сталебетонних конструкцій порівняно із залізобетонними. У сталебетонних конструкціях наявність обойми, опірній переміщенню бетону в поперечному напрямку, призводить до збільшення міцності бетону, а наявність заповнювача усередині оболонки збільшує ії стійкість. Бетон i сталь у такому поєднанні створюють найбільш сприятливі умови для одночасного сприймання навантаження.

\section{Висновки i перспективи} подальшого використання. На основі проведеного аналізу теоретичних та експериментальних досліджень зроблено висновок, що застосування сталебетону $\epsilon$ ефективним у конструкціях, працюючих на осьове стиснення, а також в елементах, які підлягають згину i позацентровому стисненню. При цьому, порівняно із залізобетонними, сталебетонні конструкції мають підвищену несучу здатність, жорсткість, тріщиностійкість, а порівняно 3 металевими - меншу металомісткість.

Результати випробувань стальних оболонок у зразках без бетонного ядра показали, що розрахунки критичних напружень i границі несучої здатності надають збиткову, порівняно 3 експериментальними результатами, відносну помилку, яка не перевищує $15 \%$. $\mathrm{Te}$, що одержані експериментальним шляхом значення критичних напружень менше від теоретичних, можна пояснити наявністю початкових недосконалостей у реальних стержнях.

Несуча здатність оболонок із заповнювачем перевищує несучу здатність порожніх оболонок у середньому в 1,7 разу. Цей результат підтверджує, що заповнювач, який перешкоджає місцевій втраті стійкості, перетворює роботу оболонки на схему чотирьох шарнірноопертих пластин [3]. Бетонне ядро i оболонка зв'язані між собою силами зчеплення дискретно по довжині і перерізу.

Порівняння теоретичних i експериментальних даних показало, що максимальна розбіжність не перевищує 9,2 \%.

Використання в будівництві сталебетонних колон прямокутного перерізу, в основу конструкції яких покладено розроблені способи розрахунків, дозволяє при більших навантаженнях та обмежених розмірах поперечних перерізів знизити витрату сталі на 28-35 \% порівняно із залізобетонними колонами.

\section{Сиисок літератури}

1. Грушко, И.М. Повышение прочности и выносливости бетона [Текст] / И.М. Грушко, А.Г. Ильин, Э.Д. Чихладзе - Харьков: Изд-во при Харьковском гос. университете, 1986. $150 \mathrm{c}$. 
2. Стороженко, Л.І. Сталезалізобетонні конструкції [Текст] / Л.І. Стороженко, О.В. Семко. - Полтава, 2001. - 55 с.

3. Чихладзе, Э.Д. Расчет сталебетонных элементов прямоугольного сечения на прочность при осевом сжатии [Текст] / Э.Д. Чихладзе, А.Д. Арсланханов // Бетон и железобетон. - 1993. - № 1. - С. 13-15.

4. Лопатто, А.Э. О свойствах бетона, твердеющего в замкнутой обойме, и жесткости трубобетонных элементов [Текст] // А.Э. Лопатто. - Строительные конструкции. - К., 1973. $232 \mathrm{c}$.

5. Глазунов, Ю.В. Вплив способів передачі поздовжнього навантаження на несучу здатність сталебетонних коротких колон прямокутного перерізу [Текст]: автореф. дис. ... канд. техн. наук: 05.23.01/ Ю.В. Глазунов. - Харків, 1997. - 22 с.

Ключові слова: сталебетон, зовнішнє армування, тензодатчики, бетонне ядро, стальна оболонка, сталебетонний елемент.

\section{Анотаціi}

Повідомлено щодо проведених теоретичних та експериментальних досліджень сталебетонних конструктивних елементів при різних способах поздовжнього навантаження $\mathrm{i}$ показано техніко-економічну ефективність застосування таких конструкцій замість сталевих і залізобетонних.

Приведены теоретические и экспериментальные исследования сталебетонных конструктивных элементов при разных способах приложения продольной нагрузки и показана технико-экономическая эффективность применения таких конструкций в сравнении со стальными и железобетонными конструктивными элементами.

A method of strength calculation of rectangular section of steel-concrete columns depending on the process of longitudinal loading has been developed. Theoretical and experimental data have been compared. Cite experiment and theoretical investigation steel concrete constructions depending on the process of longitudinal loading has been developed and method their calculation. There was executed the experimental and theoretical researches of the steel-concrete elements, working by center compression. 